\title{
A production inventory model for single vendor single buyer integrated demand with multiple production setups and rework
}

\author{
T. Sekar ${ }^{\mathrm{a}^{*}}$ and R. Uthayakumar
}

${ }^{a}$ Department of Mathematics, The Gandhigram Rural Institute - Deemed University, Gandhigram - 624 302, Dindigul, Tamilnadu, India

\begin{tabular}{l}
\hline C H R O N I C L E \\
\hline Article history: \\
Received December 2, 2016 \\
Received in revised format \\
December 10, 2016 \\
Accepted June 12017 \\
Available online \\
June 12017 \\
\hline Keywords: \\
Manufacturer's inventory \\
Buyer's inventory \\
Rework \\
Integrated demand \\
Total relevant cost
\end{tabular}

A B S T R A C T

\begin{abstract}
In this paper, an imperfect production inventory system with multi-production run for single vendor and single buyer is studied where the defective items are reworked after several production processes and there is no break down during the rework process. The model is considered for deteriorating items under two delivery policies in order to determine the delivery policy leading to the minimum holding cost of system. The objective of this model is to determine the optimal production setup, number of deliveries and lot size by minimizing the total relevant cost of the proposed vendor-buyer integrated system. To minimize the manufacturer's and buyer's holding cost, the supply of finished products are made in small quantities. The total relevant cost of the vendor and the buyer is derived and a numerical example is presented to demonstrate the utility of the model.
\end{abstract}

\section{Introduction}

In the global competition market, it is not easy to produce high quality products. But serving high quality products and providing good service can always attract customers and make them to come back. Many researchers have discussed on Economic Production Quantity (EPQ) model for multiproduction setups. But very few of them have discussed an inventory model for single vendor and single buyer integrated decreasing demand with multiple production setups. Rework process is also one important issue in reverse logistics where used products are reworked to reduce waste and environmental pollution. Rework is common in Semiconductor, Pharmaceutical, Chemical, Food industries, Textile industries, Paper industries, Glass industries, Metal processing industries and Plastic industries (Buscher \& Lindner, 2007; Chiu et al., 2007; Barketau et al., 2008). CárdenasBarrón (2008) discussed on rework with single stage production system. Singh et al. (2014) discussed on rework with multi-production setup. Recently, rework process have attracted considerable attention because of the reduction of the natural resources and the rise of the cost of raw material. Rework process play an important role in eliminating waste and effectively controlling the cost of manufacturing in a production system. Therefore, determining optimal lot size in a system that allows

\footnotetext{
* Corresponding author Tel.: +91-04257-241545, Fax: 91-04257-242007

E-mail address: sekarmat@yahoo.com (T. Sekar)

C 2018 Growing Science Ltd. All rights reserved.

doi: $10.5267 / j . u s c m .2017 .6 .001$
} 
rework is a useful objective to minimize the total inventory cost. Rework process reduces energy use and saves more natural resources for the future generations. Therefore, the companies are contributing to sustainable development.

In this paper, we consider a multi-production setups and one rework setup. By this EPQ model, it is determined that optimal production setup and optimal number of equal interval so that the total relevant cost is minimized. Since production process in each production setup is imperfect because of human mistakes, (Drury, 1978; Drury \& Prabhu, 1994), non-perfect technology or many other factors. In order to provide good service to customers, after each production setup, inspection is carried out to screen out the defective items and the deteriorating items. The defective items found are stocked separately in an inventory until reach the optimal production setup. The rework process starts immediately after determined production setups end. The serviceable items, produced in each production setup, is stored separately in an inventory and sold to customers immediately. Both serviceable and defective items are considered as deteriorating items because their values go down with time. After determined production setup ends, the defective items are sent to rework. When the waiting time of the defective items exceeds the deterioration time limit, they cannot be recovered and must be disposed. The rework process manufactures all defective items as perfect quality items. We assume that all defective items after rework are considered as new. These reworked items are sold to customers to satisfy the demand immediately. There are $m$ production setups and $n$ shipment intervals and lot sizes $(q)$. At the time of $m$ production process, the $n$-equal shipment lot sizes are exported to buyer at equal shipment interval. An economic order quantity (EOQ) model is considered at buyer's side. In each cycle, buyer receives equal lot size $(q)$ for every equal interval. Here we consider two level integrated demands one is demand at buyer's side which is linearly decreasing demand with time and another one is demand at manufacturer's side which is exponentially decreasing demand with time. The production process is considered as exponentially increasing. We consider that the items stored in manufacturer and buyer's inventory are deteriorating.

The remainder of this paper is organized as follows. In section 2, we give a literature review. In section 3 , assumptions and notations are given. The mathematical formulation for this model is given in section 4. Numerical example and sensitivity analysis are given in section 5 , and conclusions are drawn in section 6.

\section{Literature Review}

Economic Production Quantity (EPQ) model is one of the prominent research topics in production, inventory control and management. By using EPQ model, optimal quantity of items and optimal production time can be obtained. Classical EPQ model was developed under various assumptions. Since then, researchers have extended the model by relaxing one or more of its assumptions. It was assumed that the items produced are of perfect quality items in the classical EPQ model. However, imperfect quality items may be produced in reality. Salameh and Jaber (2000) presented an EPQ model for imperfect items wherein the imperfect items are screened out and sold at lower price. Thereafter, the paper was re-examined by Papachristos and Konstantaras (2006) wherein the imperfect items are withdrawn at the end of a production cycle. Chung et al. (2009) proposed a two-warehouse inventory model with imperfect items. Kumar et al. (2011) presented Economic Production lot size (EPLS) model with stochastic demand and partial backlogging shortage under imperfect quality items in which stochastic imperfect production was assumed. Yassine et al. (2012) considered disaggregating the shipments of imperfect quality items in a single production run and aggregating the shipments of imperfect items over multiple production runs. Rezaei and Salimi (2012) discussed an economic production quantity and purchasing price for items with imperfect quality when inspection shifts from buyer to supplier. Mukhopadhyay and Goswami (2015) investigated an economic production quantity model for three types of imperfect items with rework. Singh et al. (2015) presented a mathematical production inventory model for deteriorating items with time dependent demand rate under the effect 
of inflation and shortages. Recently, the economic production quantity (EPQ) model problem for single item under the assumptions of imperfect production and perfect rework has been carried out by Khanna et al. (2017).

Since deterioration affects the inventory production system, the effect of deterioration should be taken into account. The deterioration has already been studied in various papers (for example: Wagner and Whitin (1958); Covert and Philip (1973); Jolai et al. (2006)). Mishra et al. (2013) considered an inventory model for deteriorating items with time-dependent demand and time varying holding cost under partial backlogging shortage. Li et al. (2015) presented a modified EPQ model with deteriorating production system and deteriorating product where rework process was considered at the end of production setup. Pal et al. (2015) proposed a production inventory model for deteriorating item with ramp type demand allowing inflation and shortages under fuzziness in which multi-production setup was considered without rework. Jaggi et al. (2015) introduced the effect of deterioration on twowarehouse inventory model with imperfect quality items. Taleizadeh et al. (2015a) developed the economic production and inventory model in a three-layer supply chain including one distributor, one manufacturer and one retailer for a single-product and general demand functions under three scenarios. Taleizadeh et al. (2015b) developed a Vendor Managed Inventory (VMI) model for a two-level supply chain comprised of one vendor and several non-competing retailers in which both the raw material and the finished product have different deterioration rates. An EOQ model for retailer wherein deterioration rate is time dependent having their expiration dates, demand rate is linearly time dependent and nonincreasing function of time under trade credits is studied by Kaur et al. (2016). Dhandapani and Uthayakumar (2016) presented an EOQ model for fresh fruits with preservation technology investment for variable deterioration rate. Jawla and Singh (2016) introduced the preservation technology investment to reduce the deterioration rate of products for their EPQ model with imperfect items and rework. Singh et al. (2016) studied that the retailers invest in preservation technology to reduce the rate of product deterioration. A two-warehouse inventory model for deteriorating items with price dependent demand under partial backlogging was discussed by Rastogi et al. (2017).

Revamp process is likewise one critical issue backward coordination where utilized items are modified to reduce total inventory cost, waste and environmental pollution. The earliest research that focused on rework and remanufacturing process was done by Schrady (1967). Since then, researchers on rework have attracted many researchers. Koh et al. (2002) discussed on production inventory models where provider can fill the request in two options: either arranges new items externally or recovers defective items are reworked in the same cycle; and in the second policy, rework is completed after $\mathrm{N}$ cycles. Inderfuth et al. (2005) considered an EPQ model with rework and deteriorating recoverable products. Yoo et al. (2009) developed an EPQ model with imperfect production, imperfect inspection and rework. Widyadana and Wee (2012) proposed an EPQ model for deteriorating items with rework which was performed after $\mathrm{m}$ production setups. Chiu et al. (2012) improved shipment policy for a vendor-buyer system with rework and an improving delivery plan. Tai (2013) proposed an EPQ model for deteriorating/imperfect product with rework which was performed as soon as production setup ends. Sarkar et al. (2014) assumed rework for single stage production system. Hsu and Hsu (2014) considered an EPQ model under an imperfect production process with shortages backordered. Chiu et al. (2014) developed an EPQ model for multi-items with scrap, rework and multi-delivery using common cycle policy. Ullah and Kang (2014) presented a more realistic approach for the modelling of optimum lot size and total cost with a focus on the work in process inventory and the effect of rework, rejects and inspection on work in process inventory.

Goyal (1977) introduced the idea of integrating a single vendor with a single buyer as component of two entity supply line system. Banerjee (1986) presented an EPQ model where the vendor manufactures product at a finite rate and that follows a lot-for-lot policy. Later, many modifications are reported in the literature. For example, the two-level vendor and buyer problem and its related issues can be studied in Goyal (1995), Hill (1977, 1999), Valentini and Zavanella (2003), Zanoni and Grubbstrom (2004) 
and Hill and Omar (2006). Benkherouf and Omar (2010) presented a method for finding the optimal replenishment run and production plan for a single-vendor single-buyer inventory model. Hsu and Hsu (2012) proposed an integrated single-vendor single-buyer production-inventory model for items with imperfect quality and inspection errors. Yang et al (2013) discussed a vendor-buyers integrated inventory model involving quality improvement investment in a supply chain. Taleizadeh et al. (2015c) presented a model which deals with the problem of the joint determination of selling price, replenishment lot size and the number of shipments for an economic production quantity (EPQ) model with rework of defective items where multi-shipment policy is used.

For a three stage supply chain, Banerjee and Kim (1995) extended an integrated just-in-time inventory model where the demand rate, production rate, and delivery time are constant and deterministic. Munson and Rosenblatt (2001) introduced a three-level supply chain with quantity discount model. Lee and Moon (2006) proposed a coordinated inventory model with compensation policy in a threelevel supply chain. Jaber and Goyal (2008) also considered a similar problem consisting of a single raw material supplier, a single vendor, and a single buyer. Omar et al. (2013) developed an integrated just-in-time inventory model where the demand rate is linearly decreasing with time, production rate is finite, and delivery time is constant and deterministic. Tavakoli and Mirzaee (2014) proposed a coordination of a three-level supply chain under disruption using profit sharing and return policy contracts. Kundu and Chakrabarti (2015) presented the supply chain structure consists of a single manufacturer with multi-buyer where manufacturer orders a fixed quantity of raw materials from outside suppliers, process the materials and delivers the finished products in unequal shipments to each customer.

\section{Assumptions and Notations}

\subsection{Assumptions}

1. Shortages are not allowed and the rate of producing good quality items and rework must be greater than the demand rate.

2. No machine breakdown occurs in the production run time and rework period.

3. Rework rate is constant.

4. There is a replacement for a deteriorated item.

5. Deteriorating rate is constant.

6. Defective items are generated only during production period. Rework process results in only good quality items.

7. Multiple production setup inventory system is considered.

8. The demand rate at the buyer's end is $f(t)$ at any time $t$ in $(0, T)$ and assumed to be linearly decreasing with time.

9. Production rate at manufacturer's end is assumed to be exponentially increasing and demand rate is exponentially decreasing with time.

\subsection{Notations}

$\mathrm{D}(\mathrm{t}) \quad$ Demand rate (unit/year)

$\mathrm{P}(\mathrm{t}) \quad$ Production rate (unit/year)

$\mathrm{P}_{\mathrm{r}} \quad$ Rework process rate (unit/year)

$\theta_{1} \quad$ Deterioration rate at manufacturer side (unit/year)

$\theta_{2} \quad$ Deterioration rate at buyer side (unit/year) $\left(\theta_{2}>\theta_{1}\right)$

$\alpha \quad$ Percentage of good quality items

$\mathrm{m} \quad$ Number of production setup in one cycle

$\mathrm{D}_{\mathrm{i}} \quad$ Total deteriorating units (unit)

$\mathrm{K}_{\mathrm{S}} \quad$ Production setup cost (\$/setup) 


$\begin{array}{ll}\mathrm{K}_{\mathrm{r}} & \text { Rework setup cost (\$/setup) } \\ \mathrm{h}_{\mathrm{s}} & \text { Serviceable items holding cost (\$/unit/year) } \\ \mathrm{h}_{\mathrm{r}} & \text { Recoverable items holding cost (\$/unit/year) } \\ \mathrm{D}_{\mathrm{c}} & \text { Deteriorating cost (\$/unit) } \\ \mathrm{I}_{1} & \text { Serviceable inventory level in a production period } \\ \mathrm{I}_{2} & \text { Serviceable inventory level in a non -production period } \\ \mathrm{I}_{\mathrm{r} 1} & \text { Recoverable inventory level in a production period } \\ \mathrm{I}_{\mathrm{r} 2} & \text { Recoverable inventory level in a non - production period } \\ \mathrm{I}_{\mathrm{r} 1} & \text { Recoverable inventory level in a rework production period } \\ \mathrm{I}_{\mathrm{t} 1} & \text { Total serviceable inventory in a production period } \\ \mathrm{I}_{\mathrm{t} 2} & \text { Total serviceable inventory in a non - production period } \\ \mathrm{I}_{\mathrm{t} 3} & \text { Total serviceable inventory in a rework production period } \\ \mathrm{I}_{\mathrm{t} 4} & \text { Total serviceable inventory in a rework non - production period } \\ \mathrm{I}_{\mathrm{v} 1} & \text { Total recoverable inventory in } m \text { production period } \\ \mathrm{I}_{\mathrm{v} 2} & \text { Total recoverable inventory in non - production period } \\ \mathrm{I}_{\mathrm{v} 3} & \text { Total recoverable inventory in a rework production period } \\ \mathrm{TTI}_{1} & \text { Total recoverable inventory in a production period } \\ \mathrm{TTI}_{2} & \text { Total recoverable inventory in a non-production period } \\ \mathrm{TRI}_{\mathrm{T}} & \text { Total recoverable inventory } \\ \mathrm{IM}_{\mathrm{r}} & \text { Maximum inventory level of recoverable items in production setups } \\ \mathrm{IE}_{\mathrm{r}} & \text { Maximum inventory level of recoverable items when rework process start } \\ \mathrm{T}_{1} & \text { Production period } \\ \mathrm{T}_{2} & \text { Non production period } \\ \mathrm{T}_{3} & \text { Rework process period } \\ \mathrm{T}_{4} & \text { Non rework process period } \\ \mathrm{TCT} & \text { Total cost per unit time } \\ n & \text { Number of shipments } \\ \mathrm{H}_{\mathrm{b}} & \text { Inventory holding cost per unit time at the buyer's side } \\ \mathrm{S}_{\mathrm{c}} & \text { Shipment cost at buyer's side }\end{array}$

\section{Mathematical formulation of the model}

We frame the model as 3-production and 4-shipment levels which are depicted in Fig.1 and Fig. 2. Here $m$ production batch is delivered in $n$ equal interval shipments and equal shipment lot $\operatorname{size}(q)$ to the buyer as shown in the figure given below.

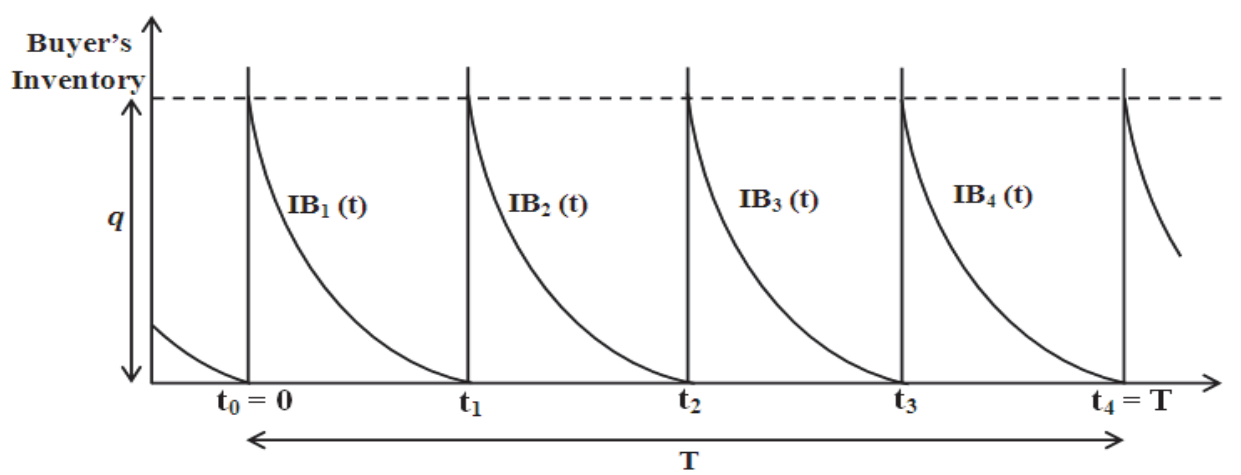

Fig. 1. Inventory level of equal lots shipments size q with $n=4$. 


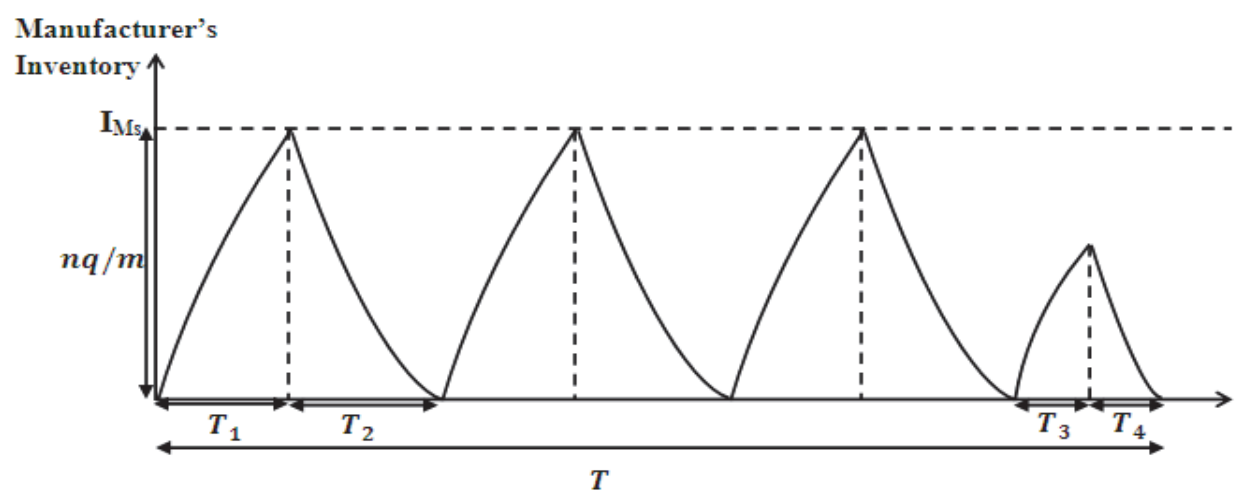

Fig. 2. Serviceable inventory level of 3 production setups and 1 rework setup.

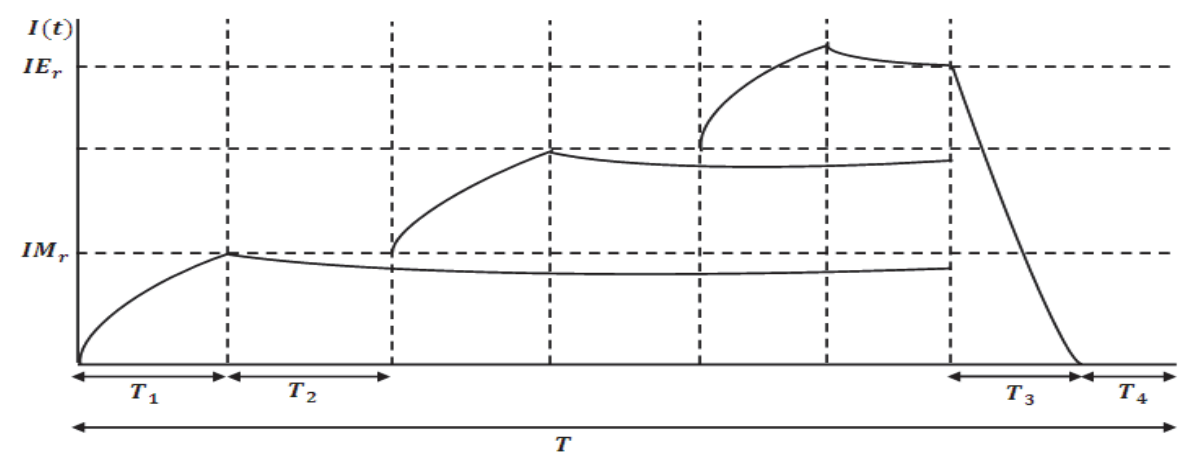

Fig. 3. Recoverable inventory level of 3 production setups and 1 rework setup.

\subsection{Buyer's total cost}

The amount of stock holding at the buyer's side during the time period $\mathrm{T}$ is calculated by assuming that $\mathrm{t}_{0}=0$. From Fig. 1 , the buyer stock level, $I B_{i}$ in any period $i=0,1,2, \ldots, n-1$ is modeled as

$\frac{d I_{B}(t)}{d t}+\theta_{2} I_{B}(t)=-D(t) \quad t_{i} \leq t \leq t_{i+1}$

where $D(t)=a-b t$ where $a$ is the intercept and $b$ is the slope of the linearly decreasing demand function.

$$
I_{B}(t)=A e^{-\theta_{2} t}+\frac{b t}{\theta_{2}}-\frac{a}{\theta_{2}}-\frac{b}{\theta_{2}^{2}}
$$

Since $I_{B}\left(t_{i+1}\right)=0$, we have

$$
I_{B}(t)=\left[\frac{a}{\theta_{2}}+\frac{b}{\theta_{2}^{2}}-\frac{b t_{i+1}}{\theta_{2}}\right] e^{\theta_{2}\left(t_{i+1}-t_{i}\right)}+\frac{b t}{\theta_{2}}-\frac{a}{\theta_{2}}-\frac{b}{\theta_{2}^{2}}
$$

Total inventory at buyer's side between $t_{i}$ to $t_{i+1}$ is

$T I_{B}(t)=\int_{t_{i}}^{t_{i+1}}\left\{\left[\frac{a}{\theta_{2}}+\frac{b}{\theta_{2}^{2}}-\frac{b t_{i+1}}{\theta_{2}}\right] e^{\theta_{2}\left(t_{i+1}-t_{i}\right)}+\frac{b t}{\theta_{2}}-\frac{a}{\theta_{2}}-\frac{b}{\theta_{2}^{2}}\right\} d t$

Integrating and using Taylor series expansion and neglecting higher orders, we get

$$
T I_{B}(t)=\left(\frac{a}{2}-\frac{b t_{i+1}}{2}\right)\left(t_{i}-t_{i+1}\right)^{2}-\frac{b}{2}\left(t_{i}^{2}-\frac{t_{i+1}^{2}}{\theta_{2}}\right)
$$

where $\left(t_{i}, t_{i+1}\right)$ is the cycle for $(i+1)$ th shipment. In this paper, we consider two possible policies. In the first policy we assume equal shipments interval where $t_{i}=i\left(\frac{T}{n}\right)$. For the second policy we assume equal shipments lot size where for $n$-shipments we have $q=\frac{1}{n}\left(\int_{0}^{T} D(t) d t\right)$.

For a linearly decreasing demand rate, $\mathrm{D}(t)=a-b t$, we have $t_{i}=\left(\frac{1}{b}\right)\left\{a-\sqrt{\frac{1}{n^{2}}\left[(a n)^{2}-2 a b i n T+(i b)^{2} T^{2}\right]}\right\}$ 
Total cost per unit time at the buyer's side, TCB, is

$$
T C B=\frac{1}{T}\left[n S_{c}+H_{b} T I_{B}(t)\right]
$$

For the first policy, $t_{i}=i\left(\frac{T}{n}\right)$, TCB becomes

$$
T C B_{t}=\frac{1}{T}\left[n S_{c}+\frac{H_{b}}{24 \theta_{2} n^{2}}\left\{\left[12 a n \theta_{2}-2 b\left(\theta_{2}-1\right)\left(2 n^{3}-3 n^{2}+n\right)-12 b n^{2}\right] T^{2}-b(n+1) T^{3}\right\}\right]
$$

For the second policy, TCB becomes

$$
\begin{aligned}
& \qquad \operatorname{TCB}_{q}=\frac{1}{T}\left[n S_{c}+H_{b}\left(\frac{a}{2}-\frac{b t_{i+1}}{2}\right)\left(t_{i}-t_{i+1}\right)^{2}-\frac{b}{2}\left(t_{i}^{2}-\frac{t_{t_{i+1}}^{2}}{\theta_{2}}\right)\right] \\
& \text { where } t_{i}=\left(\frac{1}{b}\right)\left\{a-\sqrt{\frac{1}{n^{2}}\left[(a n)^{2}-2 a b i n T+(i b)^{2} T^{2}\right]}\right\}
\end{aligned}
$$

Hence we conclude that the TCB is a function of single variable T for both policies.

\section{2. Manufacturer's total cost}

Fig. 2 shows the manufacturing inventory level during the period $T$. Production is performed during $T_{1}$ time period. When production process, $\alpha P$ good quality items is produced and $(1-\alpha) P$ defective items are screened out. $T_{2}$ is the non-production period and $T_{3}$ is the rework process period. The rework process starts immediately after $m$ the production setups end. The manufacturer's inventory level in a production period is formulated as:

$$
\frac{d I_{1}\left(t_{1}\right)}{d t_{1}}+\theta_{1} I_{1}\left(t_{1}\right)=\alpha P\left(t_{1}\right)-D\left(t_{1}\right) \quad 0 \leq t_{1} \leq T_{1}
$$

where $P(t)=\lambda e^{k t}$ and $\mathrm{D}(t)=\lambda e^{-k t}, \lambda, \mathrm{k}>0$.

Since $\mathrm{I}_{1}(0)=0$, the inventory level in a production period is:

$$
\mathrm{I}_{1}\left(\mathrm{t}_{1}\right)=\frac{\lambda}{k^{2}-\theta_{1}^{2}}\left\{\left(k \alpha-\theta_{1} \alpha\right)\left(e^{k t_{1}}-e^{-\theta_{1} t_{1}}\right)+\left(k+\theta_{1}\right)\left(e^{-k t_{1}}-e^{-\theta_{1} t_{1}}\right)\right\}
$$

The total inventory in a production up time can be modeled as:

$$
\begin{aligned}
& \mathrm{I}_{\mathrm{t} 1}\left(\mathrm{t}_{1}\right)=\int_{0}^{T_{1}} \frac{\lambda}{k^{2}-\theta_{1}^{2}}\left\{\left(k \alpha-\theta_{1} \alpha\right)\left(e^{k t_{1}}-e^{-\theta_{1} t_{1}}\right)+\left(k+\theta_{1}\right)\left(e^{-k t_{1}}-e^{-\theta_{1} t_{1}}\right)\right\} d t \\
& \mathrm{I}_{\mathrm{t} 1}=\frac{\lambda}{k \theta_{1}\left(k^{2}-\theta_{1}^{2}\right)}\left\{\left(k \alpha-\theta_{1} \alpha\right)\left(\theta_{1} e^{k T}+k e^{-\theta_{1} T_{1}}\right)-\left(k+\theta_{1}\right)\left(\theta_{1} e^{-k T_{1}}-k e^{-\theta_{1} T_{1}}\right)-(\alpha+1)\left(k^{2}-\theta_{1}^{2}\right)\right\}
\end{aligned}
$$

For small value of $\theta_{1} T_{1}$ and using Taylor series expansion, we have

$$
\mathrm{I}_{\mathrm{t} 1}=\frac{(\alpha-1) \lambda T_{1}^{2}}{2}
$$

Since $I_{1}\left(T_{1}\right)=I_{M s}$, equation (9) becomes

$$
\mathrm{I}_{\mathrm{Ms}}=\frac{\lambda}{\mathrm{k}^{2}-\theta_{1}^{2}}\left\{(\alpha-1)\left(\mathrm{k}^{2}-\theta_{1}^{2}\right) \mathrm{T}_{1}+\left(\mathrm{k}^{3}+\left(\alpha+\theta_{1}\right) \mathrm{k}^{2}-\left(\alpha+\alpha \theta_{1}+\theta_{1}\right) \theta_{1} \mathrm{k}+(\alpha-1) \theta_{1}^{3}\right) \frac{\mathrm{T}_{1}^{2}}{2}\right\}
$$

The inventory level in a non-production period is represented by

$$
\frac{d I_{2}\left(t_{2}\right)}{d t_{2}}+\theta_{1} I_{2}\left(t_{2}\right)=-D\left(t_{1}\right) \quad 0 \leq t_{2} \leq T_{2}
$$

Since $\mathrm{I}_{2}\left(\mathrm{~T}_{2}\right)=0$ and we get the total inventory in a non-production period can be represented as $\mathrm{I}_{\mathrm{t} 2}=\frac{-\lambda}{\mathrm{k} \theta_{1}\left(\mathrm{k}-\theta_{1}\right)}\left\{\mathrm{e}^{-\mathrm{kT}_{2}}\left(\theta_{1}-\mathrm{k}+\mathrm{ke}^{\theta_{1} \mathrm{~T}_{2}}\right)-\theta_{1}\right\}$ 
$\mathrm{I}_{\mathrm{t} 2}=\frac{\lambda}{2} \mathrm{~T}_{2}^{2}$

Since $\mathrm{I}_{1}=\mathrm{I}_{2}$ when $t_{1}=T_{1}$ and $t_{2}=0$, we get

$\frac{\lambda}{k^{2}-\theta_{1}^{2}}\left\{\left(k \alpha-\theta_{1} \alpha\right)\left(e^{k T_{1}}-e^{-\theta_{1} T_{1}}\right)+\left(k+\theta_{1}\right)\left(e^{-k T_{1}}-e^{-\theta_{1} T_{1}}\right)\right\}=\frac{a}{k-\theta_{1}}\left\{1-e^{\left(\theta_{1}-k\right) T_{2}}\right\}$

Using Taylor series expansion and $\frac{\left(\theta_{1}-k\right)^{2} T_{2}{ }^{2}}{2}$ is very small, we approximate $T_{2}$ as:

$$
T_{2} \cong(1-\alpha) T_{1}-\frac{\left[k(\alpha+1)+\theta_{1}(1-\alpha)\right]}{2} T_{1}^{2} \text {. }
$$

The inventory level in a rework production period is represented by

$$
\begin{array}{ll}
\frac{d I_{3}\left(t_{3}\right)}{d t_{3}}+\theta_{1} I_{3}\left(t_{3}\right)=\mathrm{P}_{\mathrm{r}}\left(t_{3}\right)-D\left(t_{3}\right) & 0 \leq t_{3} \leq T_{3} \\
I_{3}\left(t_{3}\right)=\frac{\lambda}{\theta_{1}-k}\left[e^{-\theta_{1} t_{3}}-e^{-k t_{3}}\right]+\frac{P_{r}}{\theta_{1}}\left[1-e^{-\theta_{1} t_{3}}\right] & 0 \leq t_{3} \leq T_{3}
\end{array}
$$

The inventory level in a rework non-production period is represented by

$$
\begin{array}{ll}
\frac{d I_{4}\left(t_{4}\right)}{d t_{4}}+\theta_{1} I_{4}\left(t_{4}\right)=-D\left(t_{4}\right) & 0 \leq t_{4} \leq T_{4} \\
I_{4}\left(t_{4}\right)=\frac{\lambda}{k-\theta_{1}}\left[e^{-k t_{4}}-e^{\left(\theta_{1}-k\right) T_{4}} e^{-\theta_{1} t_{4}}\right] & 0 \leq t_{4} \leq T_{4}
\end{array}
$$

Using similar steps as above, the total serviceable inventory in a rework production period and the total serviceable inventory in a rework non-production period time are derived as follows:

$$
\begin{aligned}
& \mathrm{I}_{\mathrm{t} 3}=\frac{\left(\mathrm{P}_{\mathrm{r}}-\lambda\right) \mathrm{T}_{3}{ }^{2}}{2}-\frac{P_{r}}{\theta_{1}} T_{3} \\
& \mathrm{I}_{\mathrm{t} 4}=\frac{\lambda \mathrm{T}_{4}{ }^{2}}{2}
\end{aligned}
$$

Since $\mathrm{I}_{3}=\mathrm{I}_{4}$ when $t_{3}=T_{3}$ and $t_{4}=0$, we get

$$
T_{4} \cong \frac{2\left(P_{r}-\lambda\right) T_{3}+\left[\lambda\left(k+\theta_{1}\right)-\theta_{1} P_{r}\right] \mathrm{T}_{3}^{2}}{2 \lambda}
$$

The inventory level of recoverable items is shown in Fig. 3. The inventory level of recoverable items in a production period can be modeled as

$$
\frac{d I_{r 1}\left(t_{r 1}\right)}{d t_{r 1}}+\theta_{1} I_{r 1}\left(t_{r 1)}=(1-\alpha) P \quad 0 \leq t_{r 1} \leq T_{1}\right.
$$

Since $\mathrm{I}_{\mathrm{r} 1}(0)=0$, the inventory level of recoverable items in a production period is

$$
I_{r 1}\left(t_{r 1)}=\frac{\lambda(1-\alpha)}{\left(k+\theta_{1}\right)}\left[e^{k t_{r 1}}-e^{-\theta_{1} t_{r 1}}\right] \quad 0 \leq t_{r 1} \leq T_{1}\right.
$$

Using Taylor series approximation, the total recoverable inventory in a production up time in one setup is

$$
\mathrm{TTI}_{1}=\frac{\lambda(1-\alpha) \mathrm{T}_{1}^{2}}{2}
$$

Since there are $m$ production setups in one cycle, the total inventory for recoverable items in one cycle is

$$
\mathrm{I}_{\mathrm{v} 1}=\frac{m \lambda(1-\alpha) T_{1}^{2}}{2}
$$

The initial recoverable inventory level in each production setup is equal to $\mathrm{I}_{\mathrm{Mr}}$ and it can be represented as:

$\mathrm{I}_{\mathrm{Mr}}=\frac{\lambda(1-\alpha)}{\left(k+\theta_{1}\right)}\left[e^{k T_{1}}-e^{-\theta_{1} T_{1}}\right]$

Using Taylor series approximation, we get

$$
\mathrm{I}_{\mathrm{Mr}}=\lambda(1-\alpha)\left[T_{1}+\left(k-\theta_{1}\right) \frac{T_{1}{ }^{2}}{2}\right]
$$

The inventory level of recoverable items in a non-production period is:

$$
\frac{d I_{r 2}\left(t_{r 2}\right)}{d t_{r 2}}+\theta_{1} I_{r 2}\left(t_{r 2)}=0 \quad 0 \leq t_{r 2} \leq(m-1) T_{1}+m T_{2}\right.
$$


Since the inventory level $I_{r 2}(0)=\mathrm{I}_{\mathrm{Mr}}$, the inventory level of recoverable items in a non-production time for each production setup can be modeled as:

$$
I_{r 2}\left(t_{r 2)}=\mathrm{I}_{\mathrm{Mr}} \mathrm{e}^{-\theta_{1} \mathrm{t}_{\mathrm{r} 2}} \quad 0 \leq t_{r 2} \leq(m-1) T_{1}+m T_{2}\right.
$$

Using Taylor series expansion, the total inventory of recoverable items in a production down time in one setup is:

$$
\mathrm{TTI}_{2}=\sum_{k=1}^{m} \mathrm{I}_{\mathrm{Mr}}\left\{\left[(\mathrm{k}-1) \mathrm{T}_{1}+\mathrm{kT}_{2}\right]-\frac{\theta_{1}\left[(\mathrm{k}-1) \mathrm{T}_{1}+\mathrm{kT}_{2}\right]^{2}}{2}\right\}
$$

The total inventory of recoverable items in $m$ production periods can be modeled as follows:

$$
\mathrm{I}_{\mathrm{v} 2}=\sum_{k=1}^{m} \mathrm{I}_{\mathrm{Mr}}\left\{\left[(\mathrm{k}-1) \mathrm{T}_{1}+\mathrm{kT}_{2}\right]-\frac{\theta_{1}\left[(\mathrm{k}-1) \mathrm{T}_{1}+\mathrm{kT}_{2}\right]^{2}}{2}\right\}
$$

Inventory level of recoverable item in the end of production cycle is equal to maximum inventory level of recoverable items in a production setup reduced by deteriorating rate during production up time and down time. The inventory level can be formulated as follows:

$$
\mathrm{I}_{\mathrm{Er}}=\sum_{k=1}^{m} \mathrm{I}_{\mathrm{Mr}} \mathrm{e}^{-\theta_{1}\left[(\mathrm{k}-1) \mathrm{T}_{1}+\mathrm{kT}_{2}\right]}
$$

Using Taylor series expansion and then substituting $\mathrm{I}_{\mathrm{Mr}}$ in Eq. (29) we get

$$
\mathrm{I}_{\mathrm{Er}}=\sum_{k=1}^{m}\left\{\lambda(1-\alpha)\left(T_{1}+\left(k-\theta_{1}\right) \frac{T_{1}^{2}}{2}\right\}\left\{\begin{array}{r}
1-\theta_{1}\left[(\mathrm{k}-1) \mathrm{T}_{1}+\mathrm{kT}_{2}\right] \\
+\frac{\left\{\theta_{1}\left[(\mathrm{k}-1) \mathrm{T}_{1}+\mathrm{kT}_{2}\right]\right\}^{2}}{2}
\end{array}\right\}\right.
$$

The inventory level of recoverable items in a rework period can be formulated as:

$$
\begin{array}{ll}
\frac{d I_{r 3}\left(t_{r 3}\right)}{d t_{r 3}}+\theta_{1} I_{r 3}\left(t_{r 3}=-P_{r}\right. & 0 \leq t_{r 3} \leq T_{3} \\
I_{r 3}\left(t_{r 3}=\frac{P_{r}}{\theta_{1}}\left[e^{\theta_{1}\left(T_{3}-T_{r 3}\right)}-1\right]\right. & 0 \leq t_{r 3} \leq T_{3}
\end{array}
$$

The total inventory of recoverable items in a rework period is:

$I_{r 3}\left(t_{r 3}\right)=\int_{t_{r 3}=0}^{T_{3}} \frac{P_{r}}{\theta_{1}}\left[e^{\theta_{1}\left(T_{3}-T_{r 3}\right)}-1\right] d t_{r 3}$

Using Taylor series expansion, we get

$$
\mathrm{I}_{\mathrm{v} 3}=\frac{\mathrm{P}_{\mathrm{r}} \mathrm{T}_{3}^{2}}{2}
$$

When $t_{r 3}=0, I_{r 3}\left(t_{r 3}\right)=\mathrm{I}_{\mathrm{Er}}$.

$\mathrm{I}_{\mathrm{Er}}=\frac{P_{r}}{\theta_{1}}\left[e^{\theta_{1} T_{3}}-1\right]$

Since $\theta_{1} T_{3} \ll 1$ and using Taylor series expansion we have:

$$
T_{3}=\frac{\mathrm{I}_{\mathrm{Er}}}{P_{r}}
$$

Substitute $\mathrm{I}_{\mathrm{Er}}$ in equation (34) we have

$$
T_{3}=\frac{1}{P_{r}} \sum_{k=1}^{m}\left\{\lambda(1-\alpha)\left(T_{1}+\left(k-\theta_{1}\right) \frac{T_{1}{ }^{2}}{2}\right\}\left\{\begin{array}{c}
1-\theta_{1}\left[(\mathrm{k}-1) \mathrm{T}_{1}+\mathrm{kT}_{2}\right] \\
+\frac{\left\{\theta_{1}\left[(\mathrm{k}-1) \mathrm{T}_{1}+\mathrm{kT}_{2}\right]\right\}^{2}}{2}
\end{array}\right\}\right.
$$

The total recoverable inventory is

$$
\begin{aligned}
& T R I=\mathrm{I}_{\mathrm{v} 1}+\mathrm{I}_{\mathrm{v} 2}+\mathrm{I}_{\mathrm{v} 3} \\
& T R I=\frac{m \lambda(1-\alpha) \mathrm{T}_{1}{ }^{2}}{2}+\sum_{k=1}^{m} \mathrm{I}_{\mathrm{Mr}}\left\{\left[(\mathrm{k}-1) \mathrm{T}_{1}+\mathrm{kT}_{2}\right]-\frac{\theta_{1}\left[(\mathrm{k}-1) \mathrm{T}_{1}+\mathrm{kT}_{2}\right]^{2}}{2}\right\}+\frac{\mathrm{P}_{\mathrm{r}}{ }^{2}}{2}
\end{aligned}
$$

The number of deteriorating item is equal to the number of items produced minus the number of total demands. The total deteriorating units can be modeled as:

$$
D_{i}=\left(m \alpha P T_{1} f(t)+P_{r} T_{3}\right)-D(t)\left[m\left(T_{1}+T_{2}\right)+T_{3}+T_{4}\right]
$$

The total inventory cost consists of production setup cost, rework setup cost, serviceable inventory cost, recoverable inventory cost and deteriorating cost. The total inventory cost per unit time can be modeled as follows: 
$\operatorname{TCM}\left(m, T_{1}\right)=\frac{m k_{S}+k_{r}+h_{S}\left\{\left[m\left(\mathrm{I}_{\mathrm{t} 1}+\mathrm{I}_{\mathrm{t} 2}\right)+\mathrm{I}_{\mathrm{t} 3}+\mathrm{I}_{\mathrm{t} 4}\right]-T I_{B}(t)\right\}+h_{r}(T R I)+D_{c} D_{i}}{\left[m\left(\mathrm{~T}_{1}+\mathrm{T}_{2}\right)+\mathrm{T}_{3}+\mathrm{T}_{4}\right]}$

It follows from Eq. (5) and Eq. (38), the total relevant cost for the system per unit time, TRC, is

$$
T R C=T C M+T C B, T R C=\frac{\frac{1}{T} n S_{c}+m k_{s}+k_{r}+h_{s}\left[m\left(\mathrm{I}_{\mathrm{t} 1}+\mathrm{I}_{\mathrm{t} 2}\right)+\mathrm{I}_{\mathrm{t} 3}+\mathrm{I}_{\mathrm{t} 4}\right]+h_{r}(T R I)+D_{c} D_{i}+\left(\frac{H_{b}}{T}-h_{s}\right) T I_{B}(t)}{m\left(\mathrm{~T}_{1}+\mathrm{T}_{2}\right)+\mathrm{T}_{3}+\mathrm{T}_{4}}
$$

For our first policy, $t_{i}=i \frac{T}{n}$ the TRC is, denoted by $T R C_{t}$,

$$
\begin{gathered}
T R C_{t}=\frac{1}{T} n S_{c}+\left[\frac{H_{b}}{T}-\frac{h_{s}}{m\left(T_{1}+T_{2}\right)+T_{3}+T_{4}}\right]\left[\frac { 1 } { 2 4 \theta n ^ { 2 } } \left\{\left[12 a n \theta-2 b(\theta-1)\left(2 n^{3}-3 n^{2}+n\right)-12 b n^{2}\right] T^{2}-\right.\right. \\
\left.\left.b(n+1) T^{3}\right\}\right]+\quad \frac{m k_{s}+k_{r}+h_{S}\left[m(\alpha-1) \lambda T_{1}^{2}+\frac{m \lambda}{2} T_{2}^{2}-\frac{P r}{\theta} T_{3}+\left(P_{r}-\lambda\right) \frac{T_{3}^{2}}{2}+\frac{\lambda}{2} T_{4}^{2}\right]+h_{r}(T R I)+D_{c} D_{i}}{m\left(T_{1}+T_{2}\right)+T_{3}+T_{4}}
\end{gathered}
$$

For our second policy,

$$
\begin{aligned}
& T R C_{t}=\frac{1}{T} n S_{c}+\left[\frac{H_{b}}{T}-\frac{h_{s}}{m\left(T_{1}+T_{2}\right)+T_{3}+T_{4}}\right]\left[\frac { 1 } { 2 4 \theta n ^ { 2 } } \left\{\left[12 a n \theta-2 b(\theta-1)\left(2 n^{3}-3 n^{2}+n\right)-\right.\right.\right. \\
& \left.\left.\left.12 b n^{2}\right] T^{2}-b(n+1) T^{3}\right\}\right]+ \\
& \quad \frac{m k_{s}+k_{r}+h_{s}\left[m(\alpha-1) \lambda T_{1}^{2}+\frac{m \lambda}{2} T_{2}^{2}-\frac{P_{r}}{\theta} T_{3}+\left(P_{r}-\lambda\right) \frac{T_{3}^{2}}{2}+\frac{\lambda}{2} T_{4}^{2}\right]+h_{r}(T R I)+D_{c} D_{i}}{T R C_{q}=} \frac{1}{T} n S_{c}+\left[\frac{H_{b}}{T}-\frac{\left.h_{1}+T_{2}\right)+T_{3}+T_{4}}{m\left(T_{1}+T_{2}\right)+T_{3}+T_{4}}\right] T I_{B}(t) \\
& \quad+\frac{m k_{s}+k_{r}+h_{s}\left[m(\alpha-1) \lambda T_{1}^{2}+\frac{m \lambda}{2} T_{2}^{2}-\frac{P r}{\theta} T_{3}+\left(P_{r}-\lambda\right) \frac{T_{3}^{2}}{2}+\frac{\lambda}{2} T_{4}^{2}\right]+h_{r}(T R I)+D_{c} D_{i}}{m\left(T_{1}+T_{2}\right)+T_{3}+T_{4}} \\
& \text { where } t_{i}=\frac{1}{b}\left[a-\sqrt{\frac{1}{n^{2}}\left(a^{2} n^{2}-2 a b i n T+(i b)^{2} T^{2}\right)}\right] .
\end{aligned}
$$

The optimal solution must satisfy the following conditions:

$$
\begin{aligned}
& \frac{\partial\left[T R C\left(m, T_{1}\right)\right]}{\partial T_{1}}=0 \\
& \text { and } \frac{\partial\left[T R C\left(n, T_{1}\right)\right]}{\partial T_{1}}=0
\end{aligned}
$$

Also the optimal solution of $m$ and $n$, denoted by $m^{*}$ and $n^{*}$, must satisfy the following condition:

$\operatorname{TCR}\left(m^{*}-1, T_{1}\right) \geq \operatorname{TCR}\left(m^{*}, T_{1}\right) \leq \operatorname{TCR}\left(m^{*}+1, T_{1}\right)$ and

$\operatorname{TCR}\left(n^{*}-1, T_{1}\right) \geq \operatorname{TCR}\left(n^{*}, T_{1}\right) \leq \operatorname{TCR}\left(n^{*}+1, T_{1}\right)$

Since the cost function Eq. (41) and Eq. (42) are nonlinear equations and the second derivatives of Eq. (41) and Eq. (42) with respect to $T_{1}$ is extremely complicated, closed form solution of Eq. (41) and Eq. (42) cannot be derived. This means that the optimality solution cannot be guaranteed. However, by means of empirical experiments, one can conclude that Eq. (41) and Eq. (42) are convex for a small value of $T_{1}$. The optimal $T_{1}, m$ and $n$ values can be obtained using maple mathematical software.

\section{Numerical example and sensitivity analysis}

Figs. (4-6) give that the convexity behavior of the total relevant cost for both policies against $m, n$ and $T_{1}$. Fig. 4 shows that the total cost per unit time is convex for small values of $T_{1}$. The best solution for each policy is the number of production $\left(m^{*}\right)$ should be 4 and the number of shipments $\left(n^{*}\right)$ should be 3. The optimal relevant total cost for the system per unit time for each policy is $T R C_{t}=$ 244.3815 and $T R C_{q}=247.6221$ when production time $\left(T_{1}^{*}\right)=0.03306$. The lot size for the equal 
shipment policy is 27 units with a total production size of 82 and the lot sizes for the equal shipment interval policy is 26 units with total production size of 78 .

The sensitivity analysis has been performed by changing each of the parameters by $-60 \%,-40 \%$, $20 \%,+20 \%,+40 \%$ and $+60 \%$. One parameter has been taken at a time and the remaining parameters have been kept unchanged. Table 1 shows that the the total relevant $\operatorname{cost} T R C_{t}$, equal shipment interval, is sensitive to the parameters $k_{s}, k_{r}, p_{r}, a, b, \lambda, h_{s}, h_{r}, D_{c}, \theta_{1}, \theta_{2}, H_{b}$ and $s_{c}$. The total relevant cost $\left(T R C_{t}\right)$ increases when the parameters $k_{s}, k_{r}, p_{r}, \lambda, h_{s}, h_{r}, \theta_{1}, \theta_{2}, H_{b}$ and $s_{c}$ increase and $T R C_{t}$ decreases when the parameters $b$, and $\mathrm{D}_{\mathrm{c}}$ increase. Table 2 shows that the the total relevant $\operatorname{cost} T R C_{q}$, equal shipment lot size, is sensitive to the parameters $k_{s}, k_{r}, p_{r}, a, b, \lambda, h_{s}, h_{r}, D_{c}, \theta_{1}, \theta_{2}, H_{b}$ and $s_{c}$. The total relevant cost $T R C_{q}$ increases when the parameters $k_{s}, k_{r}, p_{r}, b, \lambda, h_{s}, h_{r}, \theta_{1}, H_{b}$ and $s_{c}$ increase and decrease when the parameters $D_{c}$, and $\theta_{2}$ increases. The total relevant costs $T R C_{t}$ and $T R C_{q}$ are insensitive with the parameter $k$ and fluctuation sensitive with the parameter $a$. The optimal total relevant $\operatorname{cost} T R C_{t}$ for varying parameters is shown in Fig. 7. The figure shows that the optimal total relevant cost $T R C_{t}$ is sensitive to changes in $h_{s}, h_{r}, \lambda, s_{c}$ and moderately sensitive to changes in $a, H_{b}$ and $D_{c}$ and insensitive to changes in the other parameters. The optimal total relevant $\operatorname{cost} T R C_{q}$ for varying parameters is shown in Fig. 8. The figure shows that the optimal total relevant $\operatorname{cost} T R C_{q}$ is sensitive to changes in $h_{s}, h_{r}, s_{c}$ and moderately sensitive to changes in $a, \theta_{1}$ and $D_{c}$ and insensitive to changes in the other parameters.

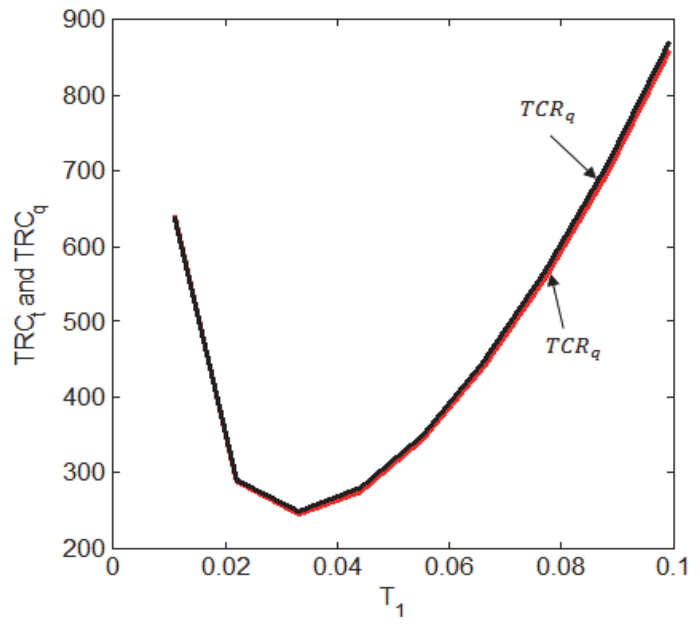

Fig. 4. Total relevant cost for both policies when $m=4$ and $n=3$ against $\mathrm{T}_{1}$

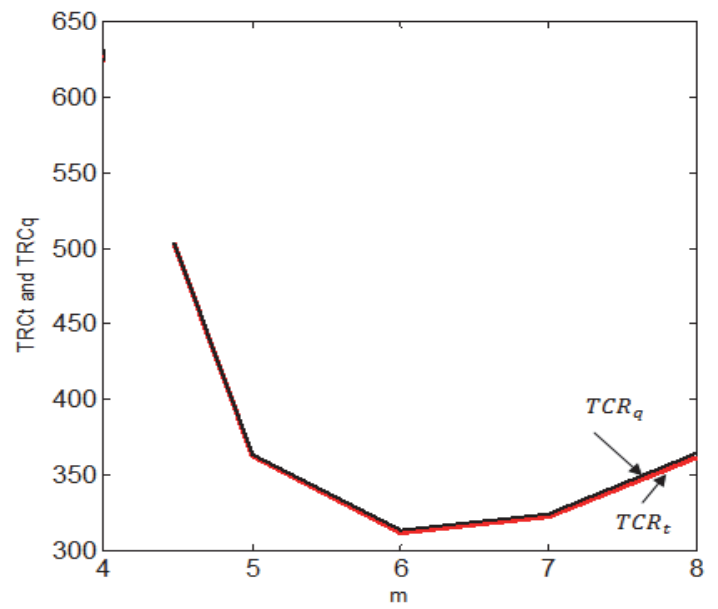

Fig. 5. Total relevant cost for both policies when $n=2$ against $m$

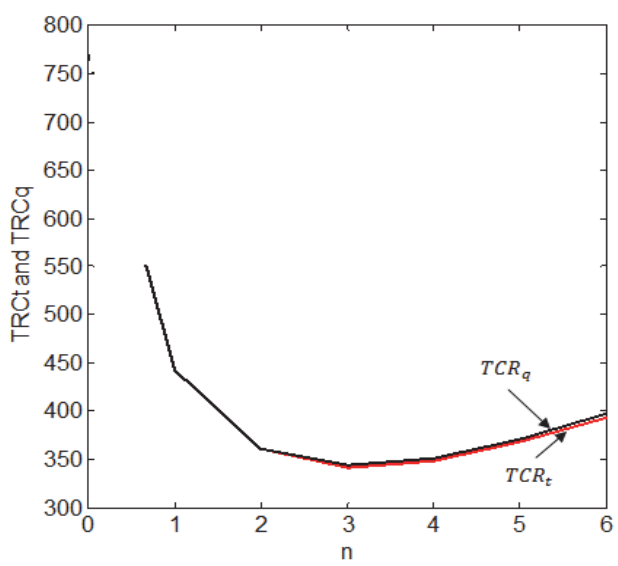

Fig. 6. Total relevant cost for both policies when $m=3$ against $n$ 
Table 1

Sensitivity analysis of $T R C_{t}$

\begin{tabular}{ccccccc}
\hline \multirow{2}{*}{ Parameters } & $-60 \%$ & $-40 \%$ & $-20 \%$ & $20 \%$ & $40 \%$ & $T 0 \%$ \\
\cline { 2 - 7 } & $T R C_{t}$ & $T R C_{t}$ & $T R C_{t}$ & $T R C_{t}$ & $T R C_{t}$ & $T R C_{t}$ \\
\hline $\mathrm{K}_{\mathrm{s}}$ & 240.8402 & 242.0207 & 243.2011 & 245.5619 & 246.7423 & 247.9228 \\
$\mathrm{~K}_{\mathrm{r}}$ & 243.9388 & 244.0864 & 244.2340 & 244.5291 & 244.6766 & 244.8242 \\
$\mathrm{P}_{\mathrm{r}}$ & 182.6555 & 208.7126 & 226.6158 & 262.0785 & 279.7362 & 297.3693 \\
$a$ & 259.1780 & 242.0132 & 244.4957 & 254.0289 & 245.5206 & 253.0852 \\
$b$ & 244.4156 & 244.4042 & 244.3929 & 244.3701 & 244.3588 & 244.3474 \\
$\lambda$ & 178.3733 & 207.5012 & 225.9413 & 262.8217 & 281.2618 & 299.7020 \\
$\mathrm{~h}_{\mathrm{s}}$ & 175.9143 & 205.7751 & 225.0783 & 263.6847 & 282.9879 & 302.2911 \\
$\mathrm{~h}_{\mathrm{r}}$ & 182.2138 & 208.9491 & 226.6653 & 262.0977 & 279.8139 & 297.5301 \\
$\mathrm{D}_{\mathrm{c}}$ & 249.4964 & 247.7914 & 246.0865 & 242.6766 & 240.9716 & 239.2666 \\
$\theta_{1}$ & 238.3595 & 241.7062 & 243.3787 & 245.0495 & 245.5261 & 245.8831 \\
$\theta_{2}$ & 244.3102 & 244.3509 & 244.3705 & 244.3883 & 244.3927 & 244.3956 \\
$\mathrm{H}_{\mathrm{b}}$ & 243.6798 & 243.9137 & 244.1476 & 244.6154 & 244.8493 & 245.0832 \\
$\mathrm{~K}_{\mathrm{S}}$ & 244.3815 & 244.3815 & 244.3815 & 244.3815 & 244.3815 & 244.3815 \\
$\mathrm{~S}_{\mathrm{c}}$ & 208.3815 & 220.3815 & 232.3815 & 256.3815 & 268.3815 & 280.3815 \\
\hline
\end{tabular}

Table 2

Sensitivity analysis of $T R C_{q}$

\begin{tabular}{ccccccc}
\hline \multirow{2}{*}{ Parameters } & $-60 \%$ & $-40 \%$ & $-20 \%$ & $20 \%$ & $40 \%$ & $60 \%$ \\
\cline { 2 - 7 } & $T R C_{q}$ & $T R C_{q}$ & $T R C_{q}$ & $T R C_{q}$ & $T R C_{q}$ & $T R C_{q}$ \\
\hline $\mathrm{K}_{\mathrm{s}}$ & 244.0808 & 245.2612 & 246.4416 & 248.8025 & 249.9829 & 251.1633 \\
$\mathrm{~K}_{\mathrm{r}}$ & 247.1794 & 247.3270 & 247.4745 & 247.7696 & 247.9172 & 248.0647 \\
$\mathrm{P}_{\mathrm{r}}$ & 183.9122 & 211.9456 & 229.8535 & 265.3209 & 282.9800 & 300.6141 \\
$a$ & 262.8846 & 245.3968 & 248.1553 & 256.1710 & 248.4088 & 256.6511 \\
$b$ & 247.2414 & 247.3683 & 247.4952 & 247.7489 & 247.8758 & 248.0027 \\
$\lambda$ & 183.3507 & 210.7417 & 229.1819 & 266.0622 & 284.5024 & 302.9426 \\
$\mathrm{~h}_{\mathrm{s}}$ & 181.5286 & 209.5583 & 228.5902 & 266.6539 & 285.6858 & 304.7177 \\
$\mathrm{~h}_{\mathrm{r}}$ & 183.4942 & 212.1897 & 229.9059 & 265.3383 & 283.0544 & 300.7706 \\
$\mathrm{D}_{\mathrm{c}}$ & 252.7369 & 251.0320 & 249.3270 & 245.9171 & 244.2122 & 242.5072 \\
$\theta_{1}$ & 241.6010 & 244.9474 & 246.6196 & 248.2897 & 248.7660 & 249.1227 \\
$\theta_{2}$ & 248.6153 & 248.0648 & 247.7886 & 247.5104 & 247.4301 & 247.3694 \\
$\mathrm{H}_{\mathrm{b}}$ & 244.1621 & 245.3154 & 246.4687 & 248.7754 & 249.9287 & 251.0821 \\
$\mathrm{~K}_{\mathrm{S}}$ & 247.6221 & 247.6221 & 247.6221 & 247.6221 & 247.6221 & 247.6221 \\
$\mathrm{~S}_{\mathrm{c}}$ & 211.6221 & 223.6221 & 235.6221 & 259.6221 & 271.6221 & 283.6221 \\
\hline
\end{tabular}

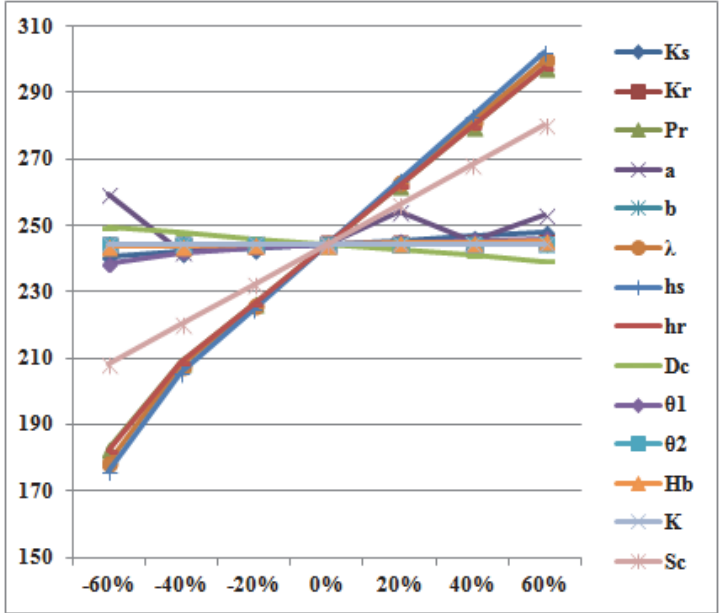

Fig. 7. $T R C_{t}$ sensitivity

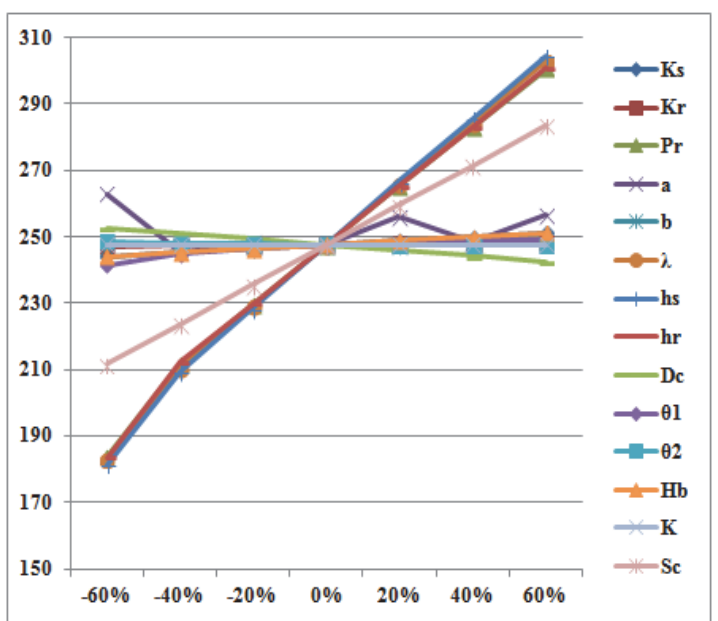

Fig. 8. $T R C_{q}$ sensitivity 


\section{Conclusion}

In this paper, we have developed a two-stage production-inventory system considering multiple production setups with deteriorating items and rework process in each cycle where the manufacturer must deliver the finished products in small quantities to minimize the buyer's holding cost. The model helps to management to determine optimal number of production setups $\left(m^{*}\right)$, number of deliveries $\left(n^{*}\right)$ and lot size $\left(q^{*}\right)$ of each deliveries by minimizing the total relevant cost under two (equal shipment interval and equal shipment lot size) policies. We also study the reworking of imperfect quality items produced on the production-inventory model. The sensitivity analysis shows that the total relevant cost under the equal shipment interval policy is increasing when production setup cost, rework setup cost, rework process rate, serviceable items holding cost, recoverable items holding cost, inventory holding cost, shipment cost increase and decrease when deteriorating cost and demand rate decrease. The total relevant cost under the equal shipment lot size policy is increasing when production setup cost, rework setup cost, rework process rate, serviceable items holding cost, inventory holding cost, shipment cost increase and decrease when deteriorating cost increase. Our numerical result shows that the equal shipment interval policy is always superior to the equal shipment lot size policy. In future, this paper can be extended as three stage production-inventory systems in which a solitary maker acquires crude materials from a solitary provider, handle them to create completed items, and then deliver the products to a single buyer where deterioration rate and holding cost are time dependent.

\section{Acknowledgement}

The authors would like to thank editor, GS team and anonymous referees for their valuable and constructive comments and suggestions. The research work has been supported by University Grants Commission (UGC-SAP), New Delhi, India.

\section{References}

Banerjee, A. (1986). A joint economic-lot-size model for purchaser and vendor. Decision Sciences, 17(3), 292-311.

Banerjee, A., \& Kim, S. L. (1995). An integrated JIT inventory model. International Journal of Operations \& Production Management, 15(9), 237-244.

Barketau, M. S., Cheng, T. E., \& Kovalyov, M. Y. (2008). Batch scheduling of deteriorating reworkables. European Journal of Operational Research, 189(3), 1317-1326.

Benkherouf, L., \& Omar, M. (2010). Optimal integrated policies for a single-vendor single-buyer timevarying demand model. Computers \& Mathematics with Applications, 60(7), 2066-2077.

Buscher, U., \& Lindner, G. (2007). Optimizing a production system with rework and equal sized batch shipments. Computers \& Operations Research, 34(2), 515-535.

Cárdenas-Barrón, L. E. (2008). Optimal manufacturing batch size with rework in a single-stage production system-a simple derivation. Computers \& Industrial Engineering, 55(4), 758-765.

Chiu, S. W., Wang, S. L., \& Chiu, Y. S. P. (2007). Determining the optimal run time for EPQ model with scrap, rework, and stochastic breakdowns. European Journal of Operational Research, 180(2), 664-676.

Chiu, Y.S.P., Lin, Y.C., Chiu, S.W., \& Ting, C.K. (2012). Joint determination of lot-size and shipment policy for a vendor-buyer system with rework and an improving delivery plan. African Journal of Business Management, 6(1), 333-340.

Chiu, S. W., Tseng, C. T., Wu, M. F., \& Sung, P. C. (2014). Multi-item EPQ model with scrap, rework and multi-delivery using common cycle policy. Journal of applied research and technology, 12(3), 615-622.

Chung, K. J., Her, C. C., \& Lin, S. D. (2009). A two-warehouse inventory model with imperfect quality production processes. Computers \& Industrial Engineering, 56(1), 193-197. 
Covert, R.P., \& Philip, G.C. (1973). An EOQ model for items with Weibull distribution deterioration. AIIE Transactions, 5(4), 323-326.

Dhandapani, J., \& Uthayakumar, R. (2017). Multi-item EOQ model for fresh fruits with preservation technology investment, time-varying holding cost, variable deterioration and shortages. Journal of Control and Decision, 4(2), 70-80.

Drury, C.G. (1978). Integrating human factors models into statistical quality control. Human Factors: The Journal of the Human Factors and Ergonomics Society, 20(5), 561-572.

Drury, C.G., \& Prabhu, P.V. (1994). Human factors in test and inspection. In G. Salvendy \& W. Karwowski (Eds.), Design of work and development of personnel in advanced manufacturing (pp. 355-401). New York: John Wiley \& Sons Inc.

Goyal, S.K. (1977). Determination of optimal production quantity for a two-stage production system. Operational Research Quarterly, 28, 865-870.

Lu, L. (1995). A one-vendor multi-buyer integrated inventory model. European Journal of Operational Research, 81(2), 312-323.

Hill, R.M. (1977). The single-vendor single-buyer integrated production-inventory model with a generalized policy. European Journal of Operational Research. 97(3), 493-499.

Hill, R. M. (1999). The optimal production and shipment policy for the single-vendor singlebuyer integrated production-inventory problem. International Journal of Production Research,37(11), 2463-2475.

Hill, R.M., \& Omar, M. (2006). Another look at the single-vendor single-buyer integrated productioninventory problem. International Journal of Production Research, 44(4), 791-800.

Hsu, J., \& Hsu, L. (2012). An integrated single-vendor single-buyer production-inventory model for items with imperfect quality and inspection errors. International Journal of Industrial Engineering Computations, 3(5), 703-720.

Hsu, L.F., \& Hsu, J.T. (2014). Economic production quantity (EPQ) models under an imperfect production process with shortages backordered. International Journal of Systems Science, 47(4), 852-867.

Inderfurth*, K., Lindner, G., \& Rachaniotis, N. P. (2005). Lot sizing in a production system with rework and product deterioration. International Journal of Production Research, 43(7), 1355-1374.

Jaber, M. Y., \& Goyal, S. K. (2008). Coordinating a three-level supply chain with multiple suppliers, a vendor and multiple buyers. International Journal of Production Economics, 116(1), 95-103.

Jaggi, C.K., Tiwari, S., \& Shafi, A. (2015). Effect of deterioration on two-warehouse inventory model with imperfect quality. Computers \& Industrial Engineering, 88, 378-385.

Jawla, P., \& Singh, S. (2016). Multi-item economic production quantity model for imperfect items with multiple production setups and rework under the effect of preservation technology and learning environment. International Journal of Industrial Engineering Computations, 7(4), 703-716.

Jolai, F., Tavakkoli-Moghaddam, R., Rabbani, M., \& Sadoughian, M. R. (2006). An economic production lot size model with deteriorating items, stock-dependent demand, inflation, and partial backlogging. Applied Mathematics and Computation, 181(1), 380-389.

Kaur, M., Pareek, S., \& Tripathi, R.P. (2016). Optimal ordering policy with non- increasing demand for time dependent deterioration under fixed life time production and permissible delay in payments. International Journal of Operations Research, 13(2), 035-046.

Khanna, A., Kishore, A., \& Jaggi, C. (2017). Strategic production modeling for defective items with imperfect inspection process, rework, and sales return under two-level trade credit. International Journal of Industrial Engineering Computations, 8(1), 85-118.

Koh, S. G., Hwang, H., Sohn, K. I., \& Ko, C. S. (2002). An optimal ordering and recovery policy for reusable items. Computers \& Industrial Engineering, 43(1), 59-73.

Kumar, M., Chauhan, A., \& Kumar, P. (2011). Economic production lot size model with stochastic demand and shortage partial backlogging rate under imperfect quality items. International Journal of Advanced Science and Technology (IJAST), 31(1), 1-22. 
Kundu, S., \& Chakrabarti, T. (2015). An integrated multi-stage supply chain inventory model with imperfect production process. International Journal of Industrial Engineering Computations, 6(4), $568-580$.

Lee. J. H., \& Moon, I. K, (2006). Coordinated inventory models with compensation policy in a threelevel supply chain, Lect. Notes in Computer Science, 3982, 600-609.

Li, N., Chan, F.T.S., Chung, S.H., \& Tai, A.H. (2015). A Modified EPQ model with deteriorating production system and deteriorating product. Proceedings of the world congress on mechanical, chemical, and material engineering (MCM 2015). Barcelona, Spain, July 20 - 21, Paper No. 249.

Mishra, V.K., Singh, L.S., \& Kumar, R. (2013). An inventory model for deteriorating items with time-dependent demand and time-varying holding cost under partial backlogging. Journal of Industrial Engineering International, 9(1), 4.

Mukhopadhyay, A., \& Goswami, A. (2015). Economic production quantity model for three type imperfect items with rework and learning in setup. An international journal of Optimization and control: Theories \& Applications, 4(1), 57-65.

Munson, C.L., \& Rosenblatt, M.J. (2001). Coordinating a three-level supply chain with quantity discount. IIE Transactions, 33(5), 371-384.

Omar, M., Sarker, R., \& Othman, W. A. M. (2013). A just-in-time three-level integrated manufacturing system for linearly time-varying demand process. Applied Mathematical Modelling, 37(3), 12751281.

Pal, S., Mahapatra, G.S., \& Samanta, G.P. (2015). A production model for deteriorating item with ramp type demand allowing inflation and shortages under fuzziness. Economic modelling, 46, 334-345.

Papachristos, S., \& Konstantaras, I. (2006). Economic ordering quantity models for items with imperfect quality. International Journal of Production Economics, 100(1), 148-154.

Rastogi, M., Singh, S., Kushwah, P., \& Tayal, S. (2017). Two warehouse inventory policy with price dependent demand and deterioration under partial backlogging. Decision Science Letters, 6(1), 1122.

Rezaei, J., \& Salimi, N. (2012). Economic order quantity and purchasing price for items with imperfect quality when inspection shifts from buyer to supplier. International Journal of Production Economics, 137(1), 11-18.

Salameh, M. K., \& Jaber, M. Y. (2000). Economic production quantity model for items with imperfect quality. International journal of production economics, 64(1), 59-64.

Sarkar, B., Cárdenas-Barrón, L. E., Sarkar, M., \& Singgih, M. L. (2014). An economic production quantity model with random defective rate, rework process and backorders for a single stage production system. Journal of Manufacturing Systems, 33(3), 423-435.

Schrady, D. A. (1967). A deterministic inventory model for reparable items. Naval Research Logistics Quarterly, 14(3), 391-398.

Singh, S., Jain, S., \& Pareek, S. (2014). An economic production model for time dependent demand with rework and multiple production setups. International Journal of Industrial Engineering Computations, 5(2), 305-314.

Singh, S. R., Agarwal, A., \& Rani, S. (2015). Mathematical Production Inventory model for deteriorating items with time dependent demand rate under the effect of inflation and shortage. International Journal of Computer \& mathematical Science, 4, 138-148.

Singh, S., Khurana, D., \& Tayal, S. (2016). An economic order quantity model for deteriorating products having stock dependent demand with trade credit period and preservation technology. Uncertain Supply Chain Management, 4(1), 29-42.

Tai, A. H. (2013). Economic production quantity models for deteriorating/imperfect products and service with rework. Computers \& Industrial Engineering, 66(4), 879-88.

Taleizadeh, A.A., Noori-daryan, M., \& Tavakkoli-Moghaddam, R. (2015a). Pricing and ordering decisions in a supply chain with imperfect quality items and inspection under buyback of defective items. International Journal of Production Research, 53(15), 4553-4582. 
Taleizadeh, A.A., Noori-daryan, M., \& Cárdenas-Barrón, L.E. (2015b). Joint optimization of price, replenishment frequency, replenishment cycle and production rate in vendor managed inventory system with deteriorating items. International Journal of Production Economics, 159, 285-295.

Taleizadeh, A., Kalantari, S.S., \& Cardenas-Barron, L.E. (2015c). Determining optimal price, replenishment lot size and number of shipments for an EPQ model with rework and multiple shipments. Journal of Industrial and Management Optimization, 11(4),1059-1071.

Tavakoli, E., \& Mirzaee, M. (2014). Coordination of a three-level supply chain under disruption using profit sharing and return policy contracts. International Journal of Industrial Engineering Computations, 5(1), 139-150.

Ullah, M., \& Kang, C.W. (2014). Effect of Rework, Rejects and Inspection on Lot Size with Work-inprocess Inventory. International Journal of Production Research, 52(8), 2448-2460.

Valentini, G., \& Zavanella, L. (2003). The consignment stock of inventories: industrial case study and performance analysis. International Journal of Production Economics, 81, 215-224.

Wagner, H.M., \& Whitin, T.M. (1958). Dynamic version of economic lot size model. Management Science, 5(1), 89-96.

Widyadana, G.A., \& Wee, H.M. (2012). An economic production quantity model for deteriorating items with multiple production setups and rework. International Journal of Production Economics, $138(1), 62-67$.

Yang, M.F., Lo, M.C., \& Lu, T.P. (2013). A vendor-buyers integrated inventory model involving quality improvement investment in a supply chain. Journal of Marine Science and Technology, 21(5), 586-593.

Yassine, A., Maddah, B., \& Salameh, M. (2012). Disaggregation and consolidation of imperfect quality shipments in an extended EPQ model. International Journal of Production Economics, 135(1), 34552.

Yoo, S. H., Kim, D., \& Park, M. S. (2009). Economic production quantity model with imperfect-quality items, two-way imperfect inspection and sales return. International Journal of Production Economics, 121(1), 255-265.

Zanoni, S., \& Grubbstrom*, R. W. (2004). A note on an industrial strategy for stock management in supply chains: modelling and performance evaluation. International Journal of Production Research, 42(20), 4421-4426.

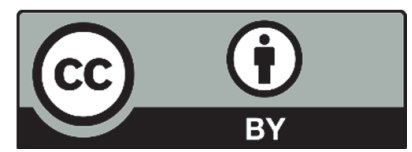

(C) 2018 by the authors; licensee Growing Science, Canada. This is an open access article distributed under the terms and conditions of the Creative Commons Attribution (CC-BY) license (http://creativecommons.org/licenses/by/4.0/). 